\title{
Unhealthy Eating Behaviors of First Year Latin- American Students, An Opportunity for Sustainable Nutritional Interventions
}

\author{
Jean Pierre Enriquez*1, Adriana Hernandez Santana ${ }^{2}$ and Sharyl Waleska Bodden ${ }^{3}$ \\ ${ }^{1}$ Masters Program in Sustainable Tropical Agriculture, Graduate Department, Zamorano University, Honduras \\ ${ }^{2}$ Human Nutrition Laboratory, Department of Food Science and Technology, Zamorano University, Honduras \\ ${ }^{3}$ Consultant at equilibrium, Honduras
}

*Corresponding author: Jean Pierre Enriquez, Masters Program in Sustainable Tropical Agriculture, Graduate Department,

Zamorano University, Honduras

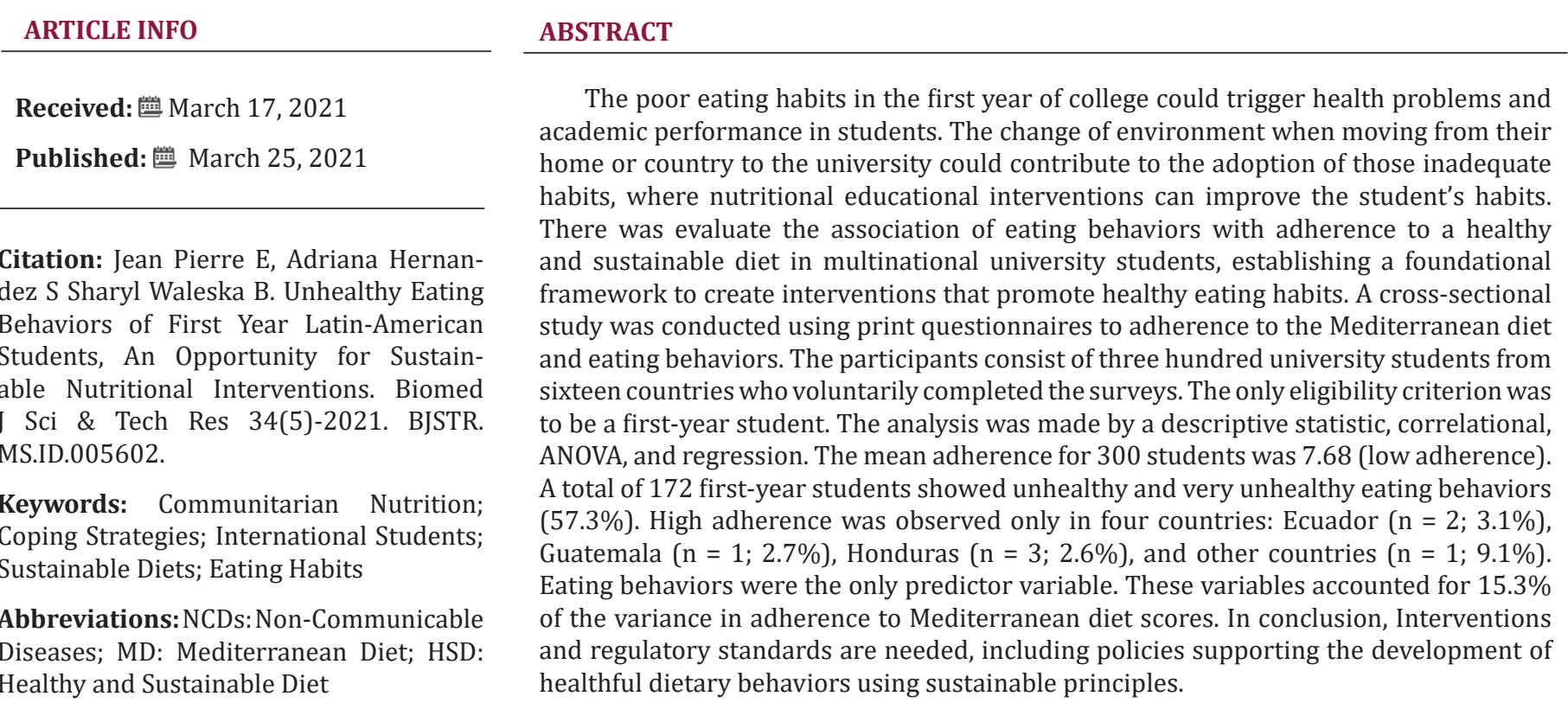

\section{Introduction}

The global food system, currently, fails to meet the need of the population, classifying it as being unsustainable [1,2], generating challenges in public health, environment, food safety, nutrition, and health [3]. On the other hand, mortality levels increase concerning all forms of malnutrition [4-6]. The most current statistics show that 2 billion adults are overweight or obese [1], while 820 million are undernourished or hungry [7]. It has been shown that the economy, culture, and social resources contribute to uneven development in health outcomes [8] such as weight gain and the development of Non-Communicable Diseases (NCDs) [9-11] with repercussions

on the diet of the population. The mass commercialization of processed foods and the rapid distribution into low and middleincome markets [12-14] has resulted in the abandonment of traditional diets and the adoption of highly processed diets, which lack in nutritional quality [15]. In terms of a healthy and sustainable diet, the Mediterranean Diet (MD) meets all established standards. It is recognized as a healthy, affordable, and environmentally sustainable eating model [16-18] being a Healthy and Sustainable Diet (HSD). It is widely documented that its adherence is linked to multiple health benefits in humans [19]. Recent meta-analyses have associated high adherence to MD and a reduction in general 
mortality, cardiovascular diseases, the incidence of certain types of cancer, diabetes, and metabolic disorders, among others [20-22].

First-year students enter a new phase of life, which is marked with diet and lifestyle changes, including making independent decisions on their own nutrition, generating vulnerability to malnutrition, sedentary lifestyle, and being overweight $[23,24]$. In this context, diet and nutrition are crucial components in the promotion and maintenance of a healthy condition [17] Furthermore, diets must meet energy needs, provide a variety of foods with nutritional quality, and be accessible and culturally appropriate [3]. Specifically, the transition to university life is characterized by major changes, increased responsibilities arising from the independence of their parents and the reduction of time as a result of studies. Due to the different interests and levels of importance, a healthy lifestyle falls behind when compared to other aspects of the student's life $[25,26]$. From another perspective, young adults tend to present bad habits, among which the omission of meals or fewer mealtimes per day stands out, as well as infrequent snacking, affecting the quality of their diet [27]. Also, there is a demonstrated tendency to a sedentary lifestyle, with the consumption of alcohol, cigarettes, among others, which leads to excess weight gain and deterioration of health $[25,28,29]$. Additionally, it has been shown that low adherence to MD can be associated with lower academic achievement [30]. Therefore, it is possible to combat poor food choices through nutritional education, while significantly reducing the environmental impacts of agriculture [31]. The current study aims to determine the association of eating behaviors with adherence to HSD in multinational university students, establishing the foundations to create interventions that improve their eating habits.

\section{Materials and Methods}

\section{Location}

This study was conducted at Zamorano University, Honduras, whose undergraduate program has a student population from around 29 countries, especially from the American continent. The students reside on campus from January until December for four years. The university has food services in the principal dining room, and there are also cafeterias, supermarkets, and restaurants offering a variety of food to students.

\section{Participants and Recruitment}

This study complies with the ethics protocols, which was approved by the Zamorano University Graduate Research Directorate meeting the ethics. The 319 first-year undergraduate students, come from 16 countries: Belize, Bolivia, Colombia, Costa Rica, Ecuador, El Salvador, United States, Guatemala, Haiti, Honduras, Mexico, Nicaragua, Panama, Paraguay, Peru, and the Dominican Republic. All of them were summoned to receive a keynote talk on nutritional education, during the first period of the 2020 academic year. The study was socialized, indicating the objective, topic, and benefits for the participant and researchers. The recruitment was voluntary, and participants were asked to sign an informed consent form. The 300 students who decided to participate received an electronic copy of the consent form.

\section{Type of Study}

An observational descriptive study of cross-sectional cohort was conducted. The eating behavior surveys were conducted in two groups on February 22 and 29, 2020, respectively. A healthy and sustainable eating model based on HSD as a lifestyle was proposed, which aimed to improve the eating behavior of first-year students.

\section{Instruments}

The data were collected through the adherence questionnaire to the Mediterranean Diet and a questionnaire of eating behaviors (both in printed form). To determine adherence to the MD, a 14-point questionnaire was applied using the PREDIMED study (Prevention with Mediterranean Diet) [31]. The questionnaire is composed of 14 direct questions about the consumption of the main foods of MD. The scores were grouped into four categories: high adherence (12-14 points), medium adherence (8-11 points), low adherence (5-7 points) and very low adherence ( $<5$ points) [26]. Subsequently, the students completed an eating behavior questionnaire with 28 multiple-choice questions, with scores grouped into four categories: healthy (23-30 points), moderately healthy (16-22 points), unhealthy (8-15 points) and very unhealthy (<8 points) [32].

\section{Statistical Analysis}

The proposed model consists of the dependent variable being adherence to the HSD, and the independent variables: country, gender, eating behaviors. The model seeks to determine the variability in adherence to the HSD. The results were summarized by descriptive statistics such as means, percentages, and standard deviation. A linear regression of the model and a Pearson correlation were carried out for the independent variables with respect to the dependent variable. The categorical variable "countries", Honduras was excluded, as it is the host country. For adherence and eating behaviors, an ANOVA was performed with Duncan mean separation for each level.

\section{Results}

Participating age were $61 \%$ men and 39\% women. Most of them, 38.67\%, came from Honduras ( $\mathrm{n}=116)$, followed by Ecuador $21.67 \%(\mathrm{n}=65)$, Guatemala $12.33 \%(\mathrm{n}=37$ ), El Salvador $11.33 \%$ ( $n=34)$, Panama 4\% ( $=12)$, Nicaragua and Others (Belize, Costa Rica, USA, Haiti, Mexico, Paraguay, Peru, and Dominican Republic) with $3.67 \%(n=11)$ each one. Finally, Colombia and Bolivia had the lowest number of participants each with $2.33 \%(n=7)$. The model had statistical significance $(\mathrm{P}<0.001)$, according to the R2 
obtained, the model explains approximately $15.3 \%$ the variability in adherence to the HSD where the only "eating behaviors" were significance. The variables of country and gender did not show predictive ability on adherence to the HSD ( $\mathrm{P}>0.05$ ), however, the variable eating behaviors have the predictive ability on the adherence to HSD ( $\mathrm{P}<0.05)$. A student from Ecuador and Bolivia have an average of 0.48 and 0.82 points more adherence to the HSD respectively than a student from Honduras. On the other hand, students from Guatemala, El Salvador, Panama, Nicaragua, Colombia, and members from other countries have, a lower adherence score than a Honduran student. The adherence average of a male was 0.31 points more than the adherence of a female (Table 1). When performing the correlations of the variables, there was an only significant correlation in eating behaviors $(\mathrm{P}<0.001$; Pearson's r: 0.344), with a low positive correlation indicating dependence between adherence to the HSD and eating behaviors.

Table 1: Linear regression on the dependent variables to the independent one: adherence.

\begin{tabular}{|c|c|c|c|c|}
\hline Predictor & Estimate & S.E. & t & P value \\
\hline Intercept $^{\mathrm{a}}$ & 4.11 & 0.60 & 6.84 & $<001$ \\
\hline Country: & & & & 0.12 \\
\hline Ecuador & 0.48 & 0.31 & -0.74 & 0.46 \\
\hline Guatemala & -0.28 & 0.37 & -0.91 & 0.36 \\
\hline El Salvador & -0.35 & 0.38 & -1.48 & 0.14 \\
\hline Panama & -0.89 & 0.60 & -0.43 & 0.67 \\
\hline Nicaragua & -0.26 & 0.62 & -0.06 & 0.95 \\
\hline Others & -0.04 & 0.62 & 1.07 & 0.29 \\
\hline Bolivia & 0.82 & 0.77 & -0.58 & 0.57 \\
\hline Colombia & -0.44 & 0.77 & & 0.19 \\
\hline Gender: & & & 0.33 & $<0.001$ \\
\hline $1-0^{*}$ & 0.31 & 0.04 & & \\
\hline Behaviors & 0.23 & & & \\
\hline
\end{tabular}

Note: ${ }^{a}$ Represent the level of reference.

S.E: Standard error.

*1 = Male, 0 = Female

\section{Adherence to Mediterranean Diet}

When performing the ANOVA for the adherence, a significant difference was found between each level of adherence $(\mathrm{P}<0.001)$. The mean adherence of the 300 participants was 7.68, ranking in low adherence (Table 2). The percentage scale was made for each country and gender based on the four levels of adherence to the HSD. High adherence was observed only in four countries: Ecuador (3.1\%), Guatemala (2.7\%), Honduras (2.6\%), and Others $(9.1 \%)$ (Table 4). All countries had medium adherence, with Bolivia being the country with the highest percentage of participants $(85.7 \%)$, followed by Ecuador (61.5\%), and the countries with the lowest number of participants with medium adherence were Others and Panama with $36.4 \%$ and $33.3 \%$ respectively. In low adherence, most of the participants were between 57.1 and 50\% (Colombia, El Salvador, Nicaragua, Others and Panama). Additionally, very low adherence was obtained in 5 countries: Panama, Guatemala, Honduras, El Salvador, and Ecuador. Regarding gender, $56.8 \%$ of men and $53.8 \%$ of women had medium adherence (Table 3 ).

Table 2: Adherence levels mean separation.

\begin{tabular}{|c|c|c|c|c|c|c|c|c|}
\hline \multicolumn{2}{|c|}{$\begin{array}{l}\text { Very Low } \\
(n=21)\end{array}$} & \multicolumn{2}{|c|}{$\begin{array}{c}\text { Low } \\
(n=106)\end{array}$} & \multicolumn{2}{|c|}{$\begin{array}{l}\text { Medium } \\
(n=167)\end{array}$} & \multicolumn{2}{|c|}{$\begin{array}{c}\text { High } \\
(n=6)\end{array}$} & \multirow{2}{*}{$\begin{array}{c}\begin{array}{c}\text { Total } \\
(n=300)\end{array} \\
\text { P value }\end{array}$} \\
\hline Mean & S.D. & Mean & S.D. & Mean & S.D. & Mean & S.D. & \\
\hline $3.19 \mathrm{~d}$ & 0.87 & $6.21 \mathrm{c}$ & 0.79 & $8.99 \mathrm{~b}$ & 0.95 & $12.14 \mathrm{a}$ & 0.37 & $<0.001$ \\
\hline
\end{tabular}

Note: S.D: Standard deviation.

Lowercase letters a-c shows mean separation. 
Table 3: Distribution of adherence levels across countries and gender.

\begin{tabular}{|c|c|c|c|c|c|c|c|c|c|}
\hline \multirow{2}{*}{ Country } & \multirow{2}{*}{$\begin{array}{c}\text { Total } \\
\text { Observations }\end{array}$} & \multicolumn{2}{|c|}{ Very Low $(n=21)$} & \multicolumn{2}{|c|}{ Low $(n=105)$} & \multicolumn{2}{|c|}{ Medium ( $n=167)$} & \multicolumn{2}{|c|}{ High $(n=6)$} \\
\hline & & $\mathbf{n}$ & $\%$ & $\mathbf{n}$ & $\%$ & $\mathbf{n}$ & $\%$ & n & $\%$ \\
\hline Bolivia & 7 & 0 & 0 & 1 & 14.3 & 6 & 85.7 & 0 & 0 \\
\hline Colombia & 7 & 0 & 0 & 4 & 57.1 & 3 & 42.9 & 0 & 0 \\
\hline Ecuador & 65 & 2 & 3.1 & 21 & 32.3 & 40 & 61.5 & 2 & 3.1 \\
\hline El Salvador & 34 & 2 & 5.9 & 17 & 50 & 15 & 44.1 & 0 & 0 \\
\hline Guatemala & 37 & 4 & 10.8 & 10 & 27 & 22 & 59.5 & 1 & 2.7 \\
\hline Honduras & 116 & 11 & 9.5 & 34 & 29.3 & 68 & 58.6 & 3 & 2.6 \\
\hline Nicaragua & 11 & 0 & 0 & 6 & 54.5 & 5 & 45.5 & 0 & 0 \\
\hline Others* & 11 & 0 & 0 & 6 & 54.5 & 4 & 36.4 & 1 & 9.1 \\
\hline Panamá & 12 & 2 & 16.7 & 6 & 50 & 4 & 33.3 & 0 & 0 \\
\hline \multicolumn{10}{|l|}{ Gender } \\
\hline Male & 183 & 10 & 5.5 & 63 & 34.4 & 104 & 56.8 & 6 & 3.3 \\
\hline Female & 117 & 11 & 9.4 & 42 & 35.9 & 63 & 53.8 & 1 & 0.9 \\
\hline
\end{tabular}

\section{Eating Behaviors}

According with the ANNOVA, there was a significant difference between each level of eating behaviors $(P<0.001)$. The mean for the eating behaviors of the 300 participants was 14.85, ranking in unhealthy behaviors. (Table 4). The percentage scale was made for each country and for each gender based on the four levels of eating behaviors (Table 5). Healthy behaviors were obtained only in $1.7 \%$ of the Honduran students and moderately healthy behaviors in all countries except Panama. Panama was the country with the highest proportion of students with unhealthy behaviors with $100 \%$ of the participants, and the $1.5 \%$ of Ecuadorians presented very unhealthy behaviors. For the gender, $1.7 \%$ of the women presented healthy behaviors. The $47 \%$ of the women and $38.9 \%$ of the men had moderately healthy behaviors, $60 \%$ of the men and $52.2 \%$ of the women had unhealthy behaviors and $1 \%$ of the men exhibited very unhealthy behaviors.

Table 4: Mean separation for eating behaviors.

\begin{tabular}{|c|c|c|c|c|c|c|c|c|}
\hline \multicolumn{2}{|c|}{$\begin{array}{c}\text { Very Unhealthy } \\
(\mathbf{n = 1})\end{array}$} & \multicolumn{2}{c|}{$\begin{array}{c}\text { Unhealthy } \\
(\mathbf{n = 1 1 )}\end{array}$} & \multicolumn{2}{c|}{$\begin{array}{c}\text { Moderately Healthy } \\
(\mathbf{n = 1 2 6})\end{array}$} & \multicolumn{2}{c|}{$\begin{array}{c}\text { Healthy } \\
(\mathbf{n}=\mathbf{2})\end{array}$} \\
\hline Mean & S.D. & Mean & S.D. & Mean & S.D. & Mean & S.D. & P value \\
\hline $7 \mathrm{~d}$ & $*$ & $12.74 \mathrm{c}$ & 1.8 & $17.76 \mathrm{~b}$ & 1.7 & $23.5 \mathrm{a}$ & 0.71 & $<0.001$ \\
\hline
\end{tabular}

Note: S.D: Standard deviation.

Lowercase letters a-c shows mean separation.

Table 5: Distribution of adherence levels across countries and gender.

\begin{tabular}{|c|c|c|c|c|c|c|c|c|c|}
\hline \multirow[t]{2}{*}{ Countries } & \multirow{2}{*}{$\begin{array}{c}\text { Total, } \\
\text { Observations }\end{array}$} & \multicolumn{2}{|c|}{$\begin{array}{l}\text { Very Unhealthy } \\
(n=1)\end{array}$} & \multicolumn{2}{|c|}{$\begin{array}{l}\text { Unhealthy } \\
(n=171)\end{array}$} & \multicolumn{2}{|c|}{$\begin{array}{l}\text { Moderately Healthy } \\
(\mathrm{n}=126)\end{array}$} & \multicolumn{2}{|c|}{$\begin{array}{l}\text { Healthy } \\
(\mathrm{n}=2)\end{array}$} \\
\hline & & $\mathbf{n}$ & $\%$ & $\mathbf{n}$ & $\%$ & $\mathbf{n}$ & $\%$ & $\mathbf{n}$ & $\%$ \\
\hline Bolivia & 7 & 0 & 0 & 3 & 42.9 & 4 & 57.1 & 0 & 0 \\
\hline Colombia & 7 & 0 & 0 & 4 & 57.1 & 3 & 42.9 & 0 & 0 \\
\hline Ecuador & 65 & 1 & 1.5 & 43 & 66.2 & 21 & 32.3 & 0 & 0 \\
\hline El Salvador & 34 & 0 & 0 & 19 & 55.9 & 15 & 44.1 & 0 & 0 \\
\hline Guatemala & 37 & 0 & 0 & 13 & 35.1 & 24 & 64.9 & 0 & 0 \\
\hline Honduras & 116 & 0 & 0 & 66 & 56.9 & 48 & 41.4 & 2 & 1.7 \\
\hline Nicaragua & 11 & 0 & 0 & 6 & 54.5 & 5 & 45.5 & 0 & 0 \\
\hline Others* & 11 & 0 & 0 & 5 & 45.5 & 6 & 54.5 & 0 & 0 \\
\hline Panama & 12 & 0 & 0 & 12 & 100 & 0 & 0 & 0 & 0 \\
\hline \multicolumn{10}{|l|}{ Gender } \\
\hline Male & 185 & 1 & 1 & 111 & 60 & 72 & 38.9 & 0 & 0 \\
\hline Female & 115 & 0 & 0 & 60 & 52.2 & 54 & 47 & 2 & 1.7 \\
\hline
\end{tabular}

Note: *Countries with less than 5 participants were grouped into Others: Belize, Costa Rica, United States, Haiti, Mexico, Paraguay, Peru, Dominican Republic. 


\section{Discussion}

Our results show that eating behaviors have predictive ability on adherence to the HSD. However, no positive association was found concerning the variables country and gender on adherence to the HSD. These findings are important to identify behaviors and food consumption patterns in students that require interventions to promote the adequate intake of healthy foods, using the MD standards for nutrition and human health as a reference. When analyzing the eating behaviors of the students, a low percentage of healthy behaviors was found. Most countries had moderately and unhealthy behaviors, except Panama, where unhealthy behaviors prevailed in its entirety, as well as in Ecuador, ranking in the lowest category regarding unhealthy behaviors. The academic transition to University is a turning point in the lifestyles of young people as students face several changes [33]. These changes include becoming independent from their parents, as well as the different cultural changes generated when students move to the country where they will study. In this case, the host country, can generate changes in terms of eating patterns due to the change in the availability of inputs, ingredients and cultural modifications generated by the change between the student's former environment [34-36] University students are in a critical period for the development of lifestyles, which are of utmost importance for their future health, where the eating behavior of their peers, their economic situation, and the ability to cook and make changes to their eating habits $[37,38]$ all have an influence.

Cervera-Burriel, et al. [39], identified that more than 91\% of the students at the University of Castilla, La Mancha, were in a situation that required changes in diet towards healthier patterns both in students living outside the home and in students living with their families. Whereas Trigueros, et al. [40], showed that the academic change to university and the pressure of the grades can generate little adaptive consequences for the consumption of healthy foods. On the other hand, the familiarity and frequency of use of Mediterranean foods increased as age increased, in a group of students whose age was 18 years and older [41], thus supporting the importance of work on nutritional education that aims to consume sustainable healthy food in university students. In this context, in the study carried out by [42], in which they related the eating habits of university students who lived away from home, reported that living away from home as a college student leads to unhealthy eating habits. In general, university students around the world must follow unhealthy eating habits [43,44,33], helping to explain the behaviors observed in this research. For this reason, eating behaviors are considered a modifiable risk factor and require early intervention in young people to avoid future social and health costs [45]. According to the adherence to HSD, our results show that most students have low compliance concerning the bases of a MD. In general, a high percentage of medium adherence was observed (55.6\%). Honduras, El Salvador, and Ecuador present the lowest adherence. Only seven participants (2.33\%) showed high adherence to MD, as previously observed in Table 4. There is scarce information on adherence to MD in college students in Latin America, and this research is the first to address it in a multicultural environment with countries of North, Central, and South America. In a study carried out on college students in Portugal, 59\% of them showed average adherence, between 6 and 9 points presenting only $12.5 \%$ high adherence [46]. Although these results are low for a mediterranean country they are far from the results of this study.

On the other hand, a study conducted on medical students at Kocaeli University in Northwestern Turkey, found that 59.1\% of women and $40.9 \%$ of men amongst first-year students showed moderate adherence using their academic knowledge on their healthy lifestyles [47]. However, other studies show that, although they have knowledge in nutrition, this does not guarantee they make better food choices where there is a greater influence of social and economic factors that leads to unhealthy choices $[47,48]$, which provides a range of opportunities to perform nutritional education interventions that emphasizes the sustainability of the food production chain. A study in college students in Bogotá and Montería (Colombia), more than $60 \%$ of the participants presented a medium adherence, while an exceedingly low adherence was observed in $30.3 \%$ of the participants from Bogotá and the $7.7 \%$ of the participants of Montería [49]. Also, in Latin America, a study from Chile, report a medium, successively low adherence [50]. Another investigation carried out by Redondo del Río [51], in which dietary intake and mediterranean adherence were analyzed in a group of college students from Valladolid (Spain), reports low and very low adherence, finding a pattern of preference for industrialized foods and a low consumption of healthy foods. These results show that students must improve their diet. Among the possible causes for these low levels of adherence, the preference to ingest processed and ultra-processed foods stand out, modifying the eating pattern and discouraging healthy food preparation. In addition to their high content of critical ingredients, add other risk factors related to obesity and chronic diseases [52].

On the other hand, [17] and [29] argue that proper adherence could prevent negative effects on health and the environment. The benefits of a MD are particularly due to the high consumption of vegetables, fruits, seafood, olive oil, and minimally processed products [53], which are available in the student's cafeteria. Students who live in university dorms show less adherence to MD [54]. Moreover, Chacón-Cuberos, et al. [55], observed that with greater adherence to MD, the stress levels decreased in college students. Martinez-Lacoba, et al. [56], showed an association between the consumption of food groups based on the recommendations of a MD and academic level. In studies related to gender, Martinez-Lacoba, et al. [57], identified that Spanish college students do not fully comply with the healthy eating recommendations. Additionally, gender is the social determinant with the greatest effect on differences in the 
consumption of groups of MD. This contrasts with our research, as gender had no impact on the consumption of foods of this dietary pattern expressed in the level of adherence $(\mathrm{P}=0.185)$, contrary to this, eating behaviors did have an impact on the level of adherence ( $\mathrm{P}<0.001)$. On the other hand, the percentages of adherence to DM in this study were higher in the males than in the females. Opposites a Galician university study, where females presented better adherence [58]. Preieri, et al. [59], using the Italian Mediterranean flavor index, found that women have greater adherence than men. Similarly, studies of New Zealand [60] and Spain [61] confirmed that gender is a factor associated with dietary patterns.

In the same context, another study which evaluated nutritional knowledge and adherence to MD in the southeastern United States [62], indicated that women have a greater nutrition knowledge, obtaining higher adherence scores in college female's students. According to our research, a study carried out in Colombia found that female sex was significantly higher in terms of a very low-quality diet and with a greater inclination for processed foods, unlike men [46]. The only statistically significant correlation for adherence to MD was the one estimated for eating behaviors. Confirming the possibility of creating institutional strategies in the nutritional field to improve behaviors and eating habits while promoting MD or HSD. The community nutrition is important, since it seeks to identify and evaluate nutritional problems to design, organize, evaluate, and implement nutritional intervention programs [63]. These interventions achieve a healthy nutritional profile over time [64], through planned activities or with specific groups as participants [65]. The intervention strategy is the way to address an identified problem to achieve the objectives of nutritional policy programs or community nutrition [66]. To meet the proposed goals, it is necessary to have an interdisciplinary group for the planning of food and nutritional policies, 65 thus promoting the participation and research process [67].

Nutritional education is one of the fundamental tools of this type of program [63], which when carried out online reflects high rates of satisfaction, understanding, and retention of the information by the participants [68]. Martinez-Lacoba et al. [59], state that students, in addition to studying subjects not related to health and that their family and are not in the university town, are factors associated with an unhealthy diet. Like evidenced in this study with unhealthy behaviors in students reinforcing the importance of conducting nutritional education and sustainability campaigns [68].

\section{Conclusion}

This study reports the need to create an institutional strategy that guides university students towards better eating behaviors since the lack of healthy practices and a distancing from healthy food choices is evident in this population. It is necessary to direct research towards institutional policies in universities that emphasize good eating habits and behaviors, instilling lifestyles and sustainable products such as DM. The MD has been described as a healthy and sustainable diet, which can be applied both in the Mediterranean and non-Mediterranean countries, in different cultures, ages, and in a complementary way, it not only offers health benefits but also benefits the environment through sustainability. In this sense, health and nutrition education should be promoted within the university environment, to improve healthy practice in food intake and to increase physical activity.

\section{Author Contribution}

J.P.E. and A.H.S. conceived and designed the study; J.P.E. performed data analysis; and J.P.E., S.W.B.A., and A.H.S. wrote the paper. All the authors provided a critical review of the manuscript. All authors have read and agreed to the published version of the manuscript.

\section{Acknowledgment}

To the Institute for Technology in Health Care for funding the purchase the publication and thereby support the formulation of public policies. To the master's program in Sustainable Tropical Agriculture (MATS) for funding the materials for the data collection. And to all the students who participate in the study.

\section{Ethical Statement}

This study complies with the ethics protocols, which was approved by the Zamorano University Graduate Research Directorate meeting the ethics. Informed consent was obtained from the students prior to data collection.

\section{References}

1. (2017) NCD Risk Factor Collaboration (NCD-RisC). Worldwide trends in body-mass index, underweight, overweight, and obesity from 1975 to 2016: a pooled analysis of 2416 population-based measurement studies in 128.9 million children, adolescents, and adults. Lancet Diabetes Endocrinol 390(10113): 2627-2642.

2. Béné $C$, Oosterveer $P$, Lamotte L, Inge D Brouwerc, Stefde Haan, et al. (2019) When food systems meet sustainability - Current narratives and implications for actions. World Dev 113: 116-130.

3. (2017) High Level Panel of Experts (HLPE) (2017) Nutrition and food systems. A report by the experts on Food Security and Nutrition of the Committee on World Food Security, Rome.

4. Hruby A, Hu FB (2015) The epidemiology of obesity: a big picture Pharmacoeconomics 33(7): 673-689.

5. Tobias DK, Hu FB (2018) The association between BMI and mortality: implications for obesity prevention. Lancet Diabetes Endocrinol 6(12): 916-917.

6. Bhaskaran K, Dos Santos Silva I, Leon DA, Ian J Douglas, Liam Smeeth (2018) Association of BMI with overall and cause-specific mortality: a population-based cohort study of 3.6 million adults in the UK. Lancet Diabetes Endrocrinol 6(12): 94-953.

7. (2019) Food and Agriculture Organization (FAO). Pan American Health Organization (PAHO), World Food Program (WFP), United Nations International Children's Emergency Fund (UNICEF). Panorama de la seguridad alimentaria y nutrición en América Latina y el Caribe pp. 1-124. 
8. Micha R, Mannar V, Afshin A, Allemandi L, Baker P, et al. (2020) Global nutrition report: action on equity to end malnutrition. Technical Report Behrman, Nina, Development Initiatives, Bristol, UK.

9. Rauber F, Da Costa ML, Steele EM, Christopher Millett, Carlos Augusto Monteiro, et al. (2018) Ultra-processed food consumption and chronic non-communicable diseases-related dietary nutrient profile in the UK (2008-2014). Nutrients 10(5): 587.

10. García Dorado SC, Cornselsen L, Smith R, Helen Walls (2019) Economic globalization, nutrition and health: a review of quantitative evidence. Glob Health 15(1): 2-19.

11. Fox A, Feng W, Asal V (2019) What is driving global obesity trends? Globalization or "modernization"? Glob Health 15(32): 2-16.

12. Popkin BM (2013) Nutrition Transition, Diet Change, and Its Implications. Encyclopedia of Human Nutrition 3: 320-328.

13. Ronto R, Wu JH, Singh GM (2018) The global nutrition transition: trends, disease burdens and policy interventions. Public Health Nutr 21(12) 2267-2270.

14. Fanzo J, Hawkes C, Udomkesmalee E, Afshin A, Allemandi L, et al. (2018) Global Nutrition Report. 2019.

15. Kopp W (2019) How western diet and lifestyle drive the pandemic of obesity and civilization diseases. Diabetes Metab Syndr Obes: Targets Ther 12: 2221-2236.

16. Burlingame B, Dernini S (2012) Sustainable Diets and Biodiversity Directions and Solutions for Policy, Research and Action. Proceedings of the International Scientific Symposium on Biodiversity and Sustainable Diets United Against Hunger, 3-5 November 2010, FAO Head-quarters, Rome.

17. Dermini S, Berry E, Serra Majem L, C La Vecchia, R Capone, et al. (2017) Med diet 4.0: The Mediterranean diet with four sustainable benefits. Public Health Nutr 20(7): 322-1330.

18. Berry EM (2019) Sustainable Food Systems and the Mediterranean Diet. Nutrients 11(9): 2229.

19. Serra Majem L, Ortiz Andrellucchi A (2018) The Mediterranean diet as an example of food and nutrition sustainability: A multidisciplinary approach. Nutr Hosp 35: 96-101.

20. Dinu M, Pagliai G, Casini A, F Sofi (2018) Mediterranean diet and multiple health outcomes: an umbrella review of meta-analyses of observational studies and randomised trials. Eur J Clin Nutr 72(1): 30-43.

21. Grosso G, Marventano S, Yang J, Agnieszka Micek, Andrzej Pajak, et al. (2017) A comprehensive meta-analysis on evidence of Mediterranean diet and cardiovascular disease: are individual components equal? Crit Rev Food Sci Nutr 57(15): 3218-3232.

22. Sánchez A, Ruíz M, Gea A, Francisca Lahortiga, Miguel A Martínez González (2016) The association between the Mediterranean lifestyle and depression. Clin Psychol Sci 4(6): 1085-1093.

23. Blázquez G, López JD, Rabanales J, Jaime López-Torres López, Carmen Ll Val Jiménez (2016) Alimentación saludable y autopercepción de salud. Aten Primaria 48(8): 535-542.

24. Woodhall Melnik J, Matheson F (2017) More than convenience: the role of habitus in understanding the food choices of fast food workers. Work Employ Soc 31(5): 800-815.

25. Chacón Cuberos R, Zurita Ortega F, Puertas P, Emily Knox (2018) Relationship between healthy habits and perceived motivational climate in sport among university students: A structural equation model. Sustainability 10: 938.

26. Benítez Benítez AM, Sánchez S, Franco Reynolds L, M Luisa Bermejo y Javier Cubero (2016) Adhesión a la dieta mediterránea en estudiantes de la Universidad de Extremadura: un recurso en educación para la salud. Revista de la Fundación Educación Médica 19(6): 287-289.
27. Saiz PG, Wang Y, Saiz JG, Guadalupe Fernández Víctor, Saiz Sánchez Carmen (2017) Estilos de vida, adherencia a la dieta mediterránea, características antropométricas en un colectivo de universitarios deficiencias de la salud. Revista Espanola de Nutrición Comunitaria 23(2).

28. Barrios Vicedo R, Navarrete Muñoz EM, García M, Sandra González Palacios, Desirée Valera Gran, et al. (2015) Una menor adherencia a la dieta mediterránea se asocia a una peor salud auto-percibida en población universitaria. Nutr Hos 31(2): 785-792.

29. Springmann MH, Godfray C, Rayner M, Mike Rayner, Peter Scarborough (2016) Analysis and valuation of the health and climate change cobenefits of dietary change. Proc Natl Acad Sci USA 113(15): 41464151.

30. Esteban Cornejo I, Izquierdo Gomez R, Gómez Martínez S, Carmen Padilla Moledo, Jose Castro Piñero, et al. (2016) Adherence to the Mediterranean diet and academic performance in youth: the UP\&DOWN study. Eur J Nutr 55(3): 1133-1140.

31. Martínez González MA, Salas Salvadó J, Estruch R, Ramón Estruch, Dolores Corella, et al. (2015) Benefits of the Mediterranean diet: insights from the PREDIMED study. Prog Cardiovasc Dis 58(1): 50-60.

32. Márquez Sandoval Y, Salazar Ruiz EN, Macedo Ojeda G, Martha Betzaida Altamirano Martínez, María Fernanda Bernal Orozco, et al. (2014) Diseño y validación de un cuestionario para evaluar el comportamiento alimentario en estudiantes mexicanos del área de la salud. Nutr Hosp $30(1): 153-164$

33. Arnett JJ (2000) Emerging adulthood: A theory of development from the late teens through the twenties. Am Psychol 55(5): 469-480.

34. Gawlikowska Sroka A, Dzięciołowska Baran E, Szczurowski J, Magdalena Szałowska Bojarun (2019) An evaluation of the dietary habits of English programme medical students in their first year of studies. Pomeranian J Life Sci 65(4): 50-54.

35. Papadaki A, Hondros GA, Scott J, Maria Kapsokefalou (2007) Eating habits of University students living at, or away from home in Greece. Appetite 49(1): 169-176

36. Sprake EF, Russell JM, Cecil JE, RJ Cooper, P Grabowski, et al. (2018) Dietary patterns of university students in the UK: A cross-sectional study. Nutr J 17: 90.

37. Alcacera MA, Marques I, Fajo Pascual M, J Puzo Foncillas, F CarmonaTorre, et al. (2008) Alcoholic beverage preference and dietary pattern in Spanish university graduates: the SUN cohort study. Eur J Clin Nutr 62(10): 1178-1186

38. Arroyo Izaga M, Rocandio AM, Ansotegui Alday L, E Pascual Apalauza, I Salces Beti, et al. (2006) Calidad de la dieta, sobrepeso y obesidad en estudiantes universitarios. Nutr Hosp 21(6): 673-679.

39. Cervera Burriel F, Serrano Urrea R, Vico C, Marta Milla Tobarra, María José García Meseguer (2013) Hábitos alimentarios y evaluación nutricional en una población universitaria. Nutr Hosp 28(2): 438-446.

40. Trigueros R, Padilla AM, Aguilar Parra JM, Patricia Rocamora, María J Morales Gázquez, et al. (2020) The influence of emotional intelligence on resilience, test anxiety, academic stress and the mediterranean diet: A study with university students. Int J Environ Res Public Health 17(6): 2071.

41. Predieri S, Sinesio F, Monteleone E, Sara Spinelli, Marta Cianciabella, et al. (2020) Gender, Age, Geographical Area, Food Neophobia and Their Relationships with the Adherence to the Mediterranean Diet: New Insights from a Large Population Cross-Sectional Study. Nutrients 12(6): 1778.

42. Bagordo F, Grassi T, Serio F, Adele Idolo (2013) Dietary habits and health among university students living at or away from home in Southern Italy. J Food Nutr Res 52(3): 164-171. 
43. El Ansari W, Stock C, Mikolajczyk RT (2012) Relationships between food consumption and living arrangements among university students in four European countries-a cross-sectional study. Nutr J 11: 1-7.

44. Tanton J, Dodd LJ, Woodfield L, Mzwandile Mabhala (2015) Eating Behaviours of British University Students: A Cluster Analysis on a Neglected Issue. Adv Prev Med 1-8.

45. Deliens T, Clarys P, De Bourdeaudhuij I, Benedicte Deforche (2014) Determinants of eating behaviour in university students: a qualitative study using focus group discussions. BMC Public Health 14: 1-12.

46. Ferreira Pêgo C, Rodrigues J, Costa A, Bruno Sousa (2019) Adherence to the Mediterranean diet in Portuguese university students. J Pharm Biomed Anal 16(1): 41-49.

47. Baydemir C, Ozgur EG, Balci S (2018) Evaluation of adherence to Mediterranean diet in medical students at Kocaeli University, Turkey. J Int Med Res 46(4): 1585-1594.

48. Chacón Cuberos R, Zurita Ortega F, Castro Sánchez M, Tamara Espejo Garcés, Asunción Martínez Martínez, et al. (2017) Análisis descriptivo del consumo de sustancias nocivas, adhesión a la dieta mediterránea y tipo de residencia en estudiantes universitarios de Granada. Revista Complutense de Educación 28(3): 823-838.

49. Villaquiran AF, Cuero P, Ceron GM, Armando Ordoñez, Sandra Jácome (2020) Características antropométricas, hábitos nutricionales, actividad física y consumo de alcohol en estudiantes universitarios. Revista Salud UIS 52(2): 109-118.

50. Vinaccia Alpi S, Serra Majem L, Ruano Rodriguez C, Quintero Maria Fernanda, Quiceno Japcy, et al. (2019) Adherencia a la dieta mediterránea en población universitaria colombiana. Nutr Clín y Diet Hosp 39(1): 93 100.

51. Rodríguez FJ, Oteiza LR, Carvajal JG, Norman Guillermo Macmillan Kuthe, Patricio Solis Urra (2013) Estado nutricional y estilos de vida en estudiantes universitarios de la Pontificia Universidad Católica de Valparaíso. Univ Salud 15(2): 123-135.

52. Redondo M, De Mateo B, Carreño L, José Manuel Marugán de Miguelsanz, Marina Fernández McPhee, et al. (2016) Ingesta dietética y adherencia a la dieta mediterránea en un grupo de estudiantes universitarios en función de la práctica deportiva. Nutr Hosp 33(5): 583.

53. Hernández A, Di Iorio AB, Tejada OA (2018) Contenido de azúcar, grasa y sodio en alimentos comercializados en Honduras, según el etiquetado nutricional: prueba para la regulación de alimentos procesados y ultraprocesados. Rev Esp Nutr Hum Diet 22(2): 108-116.

54. Sánchez Sánchez ML, García Vigara A, Hidalgo Mora JJ, Miguel Ángel García Pérez, Juan Tarín, et al. (2020) Mediterranean diet and health: A systematic review of epidemiological studies and intervention trials. Maturitas 136: 25-17.

55. El Kassas G, Ziade F (2016) Exploration of the dietary and lifestyle behaviors and weight status and their self-perceptions among health sciences university students in north Lebanon. BioMed Res Int: 9762396.
56. Chacón Cuberos R, Zurita Ortega F, Olmedo Moreno EM, Manuel Castro Sánchez (2019) Relationship between academic stress, physical activity and diet in university students of education. Behav Sci 9(6): 59.

57. Martinez Lacoba R, Pardo Garcia I, Amo Saus E, Francisco Escribano Sotos (2020) Social determinants of food consumption based on Mediterranean diet pyramid: A cross-sectional study of university students. PLoS ONE 15: e0227620.

58. Cadarso Suárez A, Dopic Calvo X, Iglesias Soler E, Cadarso Suarez, Carmen Maria, et al. (2017) Calidad de vida relacionada con la salud y su relación con la adherencia a la dieta mediterránea y la actividad física en universitarios de Galicia. Nutr Clín Diet Hosp 37(2): 42-49.

59. Predieri S, Sinesio F, Monteleone E, Sara Spinelli, Marta Cianciabella, et al. (2020) Gender, Age, Geographical Area, Food Neophobia and Their Relationships with the Adherence to the Mediterranean Diet: New Insights from a Large Population Cross-Sectional Study. Nutrients 12(6): 1778

60. Beck KL, Jones B, Ullah I, S A McNaughton, S J Haslett, et al. (2017) Associations between dietary patterns, socio-demographic factors and anthropometric measurements in adult New Zealanders: an analysis of data from the 2008/09 New Zealand Adult Nutrition Survey. European Journal of Nutrition 57(4): 1421-1433

61. Martinez Lacoba R, Pardo Garcia I, Amo Saus E, Francisco Escribano Sotos (2018) Socioeconomic, demographic and lifestyle-related factors associated with unhealthy diet: a cross-sectional study of university students. BMC Public Health 18(1): 1241.

62. Bottcher MR, Marincic PZ, Nahay KL, Brittany E Baerlocher, Amy W Willis, et al. (2017) Nutrition knowledge and Mediterranean diet adherence in the southeast United States: Validation of a field-based survey instrument. Appetite 111: 166-176.

63. Aracenta J, Pérez C, Serra L (2006) Nutrición Comunitaria. Rev Med Univ Navarra 50(4): 39-45.

64. Aranceta J (2010) Nuevos retos de la nutrición comunitaria. Rev Esp Nutr Com 16(1): 51-55.

65. Aranceta J (2013) Nutrición comunitaria. In: Elsevier Masson (eds.) Nutrición comunitaria (Community Nutrition) (3 ${ }^{\text {rd }}$ Edn.)., ES: Elsevier, Barcelona, Spain, p. 1-20.

66. Aranceta J (2013) Estrategias de intervención en nutrición comunitaria Mecanismos de participación y evaluación. In: Elsevier Masson (Eds.)., Nutrición comunitaria (Community Nutrition) ( $3^{\text {rd }}$ Edn.)., ES: Elsevier, Barcelona, Sain, p. 32-41.

67. Angarita C (2010) Desafíos de la investigación en nutrición comunitaria Rev Esp Nutr Com 16(1): 24-29.

68. Thomson J, Goodman M, Landry A, Annie Donoghue, Audrey Chandler et al. (2018) Feasibility of online nutrition education in the workplace: working toward healthy lifestyles. J Nutr Educ Behav 50(9): 868-875.

\section{ISSN: 2574-1241}

DOI: 10.26717/BJSTR.2021.34.005602

Jean Pierre Enriquez. Biomed J Sci \& Tech Res

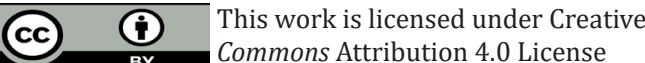

Submission Link: https://biomedres.us/submit-manuscript.php

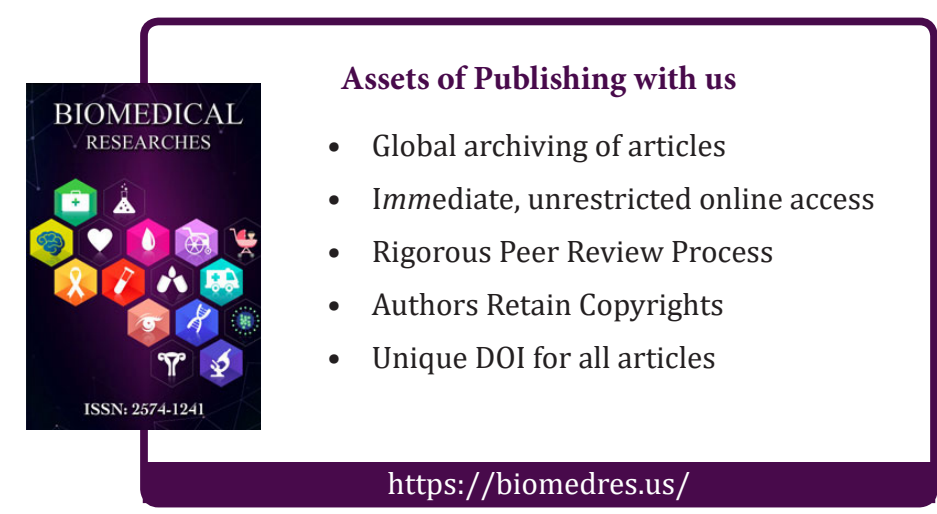

